\title{
OPTIMASI KARAKTERISTIK KUALITAS LEAD- SLAG PERISAI RADIASI BETON MENGGUNAKAN METODE GREY-TAGUCHI DESIRABILITY FUNCTION
}

\author{
Sri Winarni ${ }^{1, a)}$, Budhi Handoko ${ }^{\text {b) }}$ \\ ${ }^{1}$ Departemen Statistika FMIPA UNPAD, Jl. Raya Bandung-Sumedang KM 21 . \\ Email: ${ }^{a)}$ sri.winarni@unpad.ac.id, b)budhihandoko1980@gmail.com
}

\begin{abstract}
Abstrak
Perisai radiasi yang digunakan untuk melindungi dari bahaya radiasi merupakan salah satu masalah penting dalam bidang fisika nuklir. Beton merupakan bahan yang efektif, fleksibel dan ekonomis digunakan untuk perisai radiasi. Dalam perisai radiasi beton, berbagai macam bahan dapat digunakan untuk melemahkan foton. Lead-slag perisai beton yang digunakan dalam aplikasi nuklir selain melindungi property harus memiliki karakteristik kualitas yang optimal. Tujuan dari penelitian ini adalah mendapatkan komposisi faktor pembentukan perisai radiasi beton sehingga didapatkan kualitas perisai radiasi beton yang optimal. Metode grey-taguchi desirability function digunakan dengan mempertimbangkan beberapa karakteristik kualitas yang diukur secara simultan. Hasil optimasi didapatkan pada faktor perbandingan air -semen 0,42, kandungan semen $390 \mathrm{~kg} / \mathrm{m}^{3}$, perbandingan volume lead-slag agregat $60 \%$ dan perbandingan silica-semen 0,15 .
\end{abstract}

Kata-kata kunci: optimasi, grey-taguchi desirability function, lead-slag perisai radiasi beton

\begin{abstract}
Radiation shields are used to protect from the harmful effects of radiation is one of the important problems in the field of nuclear physics. Concrete is a material that is effective, flexible and economically used for radiation shielding. In concrete radiation shielding, a variety of materials can be used to attenuate photons. Lead-slag concrete shielding used in nuclear applications in addition to protecting the property must have the characteristics of optimal quality. The purpose of this research is to get the composition of the factors formation of radiation shielding concrete to obtain quality concrete optimal radiation shield. Grey-Taguchi method desirability function is used by considering some quality characteristics measured simultaneous. The results obtained in the optimization factor water-cement ratio of 0.42 , cement content of $390 \mathrm{~kg} / \mathrm{m}^{3}$, volume fraction lead-slag aggregate of $60 \%$ and silica fumecement ratio of 0.15 .
\end{abstract}

Keywords: optimizaion, grey-taguchi desirability function, lead-slag radiation shielding concrete.

\section{PENDAHULUAN}

Perisai radiasi merupakan alat yang digunakan sebagai penangkal sinar radiasi yang dipancarkan dari bahan nuklir tertentu. Kualitas optimum sebuah perisai sangat ditentukan oleh komposisi bahan yang digunakan dalam proses pembuatannya. Perisai yang berkualitas tidak hanya diukur dari satu 
karakteristik saja, melainkan beberapa karakteristik dipertimbangkan secara simultan untuk menentukan apakah perisai tersebut memiliki kualitas yang baik atau tidak.

Optimasi kualitas merupakan upaya untuk mendapatkan komposisi faktor yang menghasilkan kualitas optimum. Kualitas suatu produk seringkali tidak hanya mempertimbangkan satu karakteristik kualitas saja, melainkan beberapa karakteristik dipertimbangkan secara simultan. Proses optimasi dengan mempertimbangkan lebih dari satu respon (karakteristik produk) disebut dengan optimasi multirespon [1]. Optimasi kualitas tidak hanya digunakan pada dunia industri manufaktur saja melainkan juga dapat digunakan pada bidang fisika.

Desain eksperimen yang sering digunakan dalam proses optimasi kualitas adalah desain taguchi. Desain taguchi merupakan desain eksperimen yang digunakan untuk pendapatkan produk yang bersifat robust (kokoh). Perlakuan yang dicobakan dalam desain taguchi dapat berupa cross array atau ortogonal array [7].

Analisis yang umum digunakan pada desain taguchi adalah metode signal-to-noise ratio (SNR). Metode SNR digunakan pada desain taguchi satu respon, sedangkan untuk desain taguchi multi respon dapat digunakan metode grey-taguchi. Pada penelitian ini metode grey-taguchi akan digabungkan dengan desirability function [2].

Kasus yang akan digunakan pada penelitian ini diambil dari jurnal fisika modern yaitu mengenai metode optimasi secara simultan pada karakteristik kualitas Lead-Slag Radiation Shielding Concrete (LSRSC), [4]. Lead-slag perisai radiasi beton merupakan alat yang digunakan untuk menangkal sinar radiasi dari mesin nuklir. Lead-slag perisai beton yang digunakan dalam aplikasi nuklir selain melindungi property harus memiliki karakteristik kualitas yang optimal. Beton merupakan bahan yang efektif, fleksibel dan ekonomis digunakan untuk perisai radiasi. Dalam perisai radiasi beton, berbagai macam bahan dapat digunakan untuk melemahkan foton. Dalam kasus ini dicobakan beberapa komposisi bahan yang digunakan. Terdapat empat faktor dan empat respon yang diukur sebagai karakteristik kualitas lead-slag perisai radiasi beton. Faktor dan respon yang digunakan pada kasus ini diberikan pada Tabel 1.1.

Tabel 1.1 Faktor dan Respon Percobaan

\begin{tabular}{|c|c|c|c|c|}
\hline \multicolumn{5}{|c|}{ Faktor Percobaan } \\
\hline & \multirow{2}{*}{ Faktor } & \multicolumn{3}{|c|}{ Taraf } \\
\hline & & 1 & 2 & 3 \\
\hline A & Perbandingan air-semen & 0,42 & 0,45 & 0,48 \\
\hline B & Kandungan semen $(\mathrm{Kg} / \mathrm{m} 3)$ & 330 & 360 & 390 \\
\hline $\mathrm{C}$ & Perbandingan volume lead-slag agregat (\% & 40 & 50 & 60 \\
\hline $\mathrm{D}$ & Perbandingan silica-semen & 0,05 & 0,1 & 0,15 \\
\hline \multicolumn{5}{|c|}{ Respon } \\
\hline & Y1 & \multirow{2}{*}{\multicolumn{3}{|c|}{$\begin{array}{c}\text { Slump } \\
\text { unit weight }\end{array}$}} \\
\hline & Y2 & & & \\
\hline & Y3 & \multicolumn{3}{|c|}{ koefisien peredam gamma } \\
\hline & Y4 & \multicolumn{3}{|c|}{ kuat tekan } \\
\hline
\end{tabular}

Tujuan dari penelitian ini adalah mendapatkan komposisi faktor pembentukan perisai radiasi beton sehingga didapatkan kualitas perisai radiasi beton yang optimal. Metode grey-taguchi desirability function digunakan dengan mempertimbangkan beberapa karakteristik kualitas secara simultan.

\section{METODE PENELITIAN}

Metode analisis yang digunakan dalam penelitian ini adalah gabungan antara metode grey-taguchi dengan desirability function. Metode ini digunakan untuk melakukan proses optimasi multi respon. Prinsip analisis optimasi multi respon adalah mengkonversi masing-masing respon pada skala 0 sampai 1. Kemudian membentuk satu fungsi tujuan yang merupakan gabungan dari seluruh respon 
yang telah dikonversi. Dari fungsi tujuan yang terbentuk dapat ditentukan komposisi faktor yang menghasilkan respon optimum secara simultan.

Pada metode grey-taguchi desirability function, konversi respon dilakukan menggunakan desirability function, selanjutnya pembentukan fungsi tujuan dilakukan dengan metode grey-taguchi. Tahapan analisis yang dilakukan pada penelitian ini adalah sebagai berikut : [2]

\section{a. Mengkonversi respon dengan desirability function.}

Fungsi desirability merupakan suatu transformasi geometrik dari nilai respon menjadi bernilai 0 sampai dengan $1\left(0 \leq d_{i} \leq 1\right)$. Nilai ini menunjukkan tingkat kedekatan respon terhadap targetnya. Respon yang berada pada selang nilai target yang ditentukan memiliki nilai desirability nol sampai satu $\left(0<d_{i}<1\right)$. Sedangkan respon yang sangat dekat sekali dengan nilai target memiliki nilai desirability sebesar satu $\left(d_{i}=1\right)$. Sebaliknya untuk respon yang berada diluar selang target yang ditentukan maka nilai desirability-nya adalah nol $\left(d_{i}=0\right)$. [5]

Berdasarkan tujuannya, fungsi desirability dapat dikategorikan menjadi tiga, yaitu :nominal-thebest (NB), larger-the-better (LB) dan smaller-the-better (SB). Jika dimisalkan $T$ adalah nilai target yang diinginkan, $L$ adalah batas bawah target, dan $U$ adalah batas atas target $(L \leq T \leq U)$, maka bentuk fungsi desirability dari masing-masing kategori tersebut adalah sebagai berikut : [7].

i. Larger-the-better (LB)

Digunakan untuk memaksimumkan respon, memiliki bentuk fungsi individual desirability seperti pada Persamaan (2.1).

$$
d=\left\{\begin{array}{ccc}
0 & ; & y<L \\
\left(\frac{y-L}{T-L}\right)^{r} & ; & L \leq y \leq T \\
1 & ; & y>T
\end{array}\right.
$$

ii. Smaller-the-better (SB)

Digunakan untuk meminimumkan respon, bentuk fungsi desirability pada kategori ini diberikan pada Persamaan (2.2).

$$
d=\left\{\begin{array}{ccc}
1 & ; & y<T \\
\left(\frac{u-y}{U-T}\right)^{r} & ; & T \leq y \leq U \\
0 & ; & y>U
\end{array}\right.
$$

\section{iii. Nominal-the-best (NB)}

Digunakan untuk respon pada nilai target, memiliki bentuk fungsi individual desirability seperti pada persamaan (2.3). 


$$
d=\left\{\begin{array}{ccc}
0 & ; & y<L \\
\left(\frac{y-L}{T-L}\right)^{r} & ; & L \leq y \leq T \\
\left(\frac{y-L}{T-L}\right)^{r} & ; & T \leq y \leq U \\
0 & ; & y>U
\end{array}\right.
$$

Indeks $r$ merupakan pembobotan yang menunjukkan penekanan jauh dekatnya respon terhadap nilai target. Nilai $0<r<1$ menunjukkan penekanan yang kurang pada targetnya. Semakin besar nilai $r$ maka semakin jauh nilai respon dari targetnya. Nilai $r=1$ menunjukkan kepentingan yang sama terhadap target. Pada nilai ini fungsi desirability berbentuk linear. Nilai $r>1$ menunjukkan penekanan yang lebih pada targetnya. Kondisi yang ideal adalah nilai desirability yang tinggi menunjukkan nilai respon yang dekat dengan targetnya

\section{b. Menentukan nilai Grey Relational Coefficient (GRC).}

Metode grey-taguchi merupakan gabungan dari metode taguchi dengan grey relational analysis. Setelah dilakukan konversi terhadap respon langkah berikutnya adalah menentukan nilai GRG menggunakan Persamaan 2.5. [2]

$$
\gamma\left(x_{o j}, x_{i j}\right)=\frac{\Delta \operatorname{Min}+\zeta \Delta M a x}{\Delta_{i j}+\zeta \Delta M a x}
$$

dengan $i=1,2, \ldots, m j=1,2, \ldots n$

$\Delta_{i j}=x_{0 j}-x_{i j} \quad$ merupakan perbedaan absolut antara nilai $x_{0}(j)$ dengan $x_{i}(j)$. $\zeta$ merupakan koefisien identifikasi dan digunakan untuk mengimbangi pengaruh $\Delta_{\max }$ ketika memiliki nilai terlalu besar. Pada kasus ini diambil nilai $\zeta=0,5$.

$$
\begin{aligned}
& \Delta \operatorname{Min}=\operatorname{Min}\left\{\Delta_{i j}, i=1,2, \ldots, m_{;} j=1,2, \ldots, n\right\} \\
& \Delta \operatorname{Max}=\operatorname{Max}\left\{\Delta_{i j}, i=1,2, \ldots, m ; j=1,2, \ldots, n\right\}
\end{aligned}
$$

\section{c. Menentukan nilai Grey Relational Grade (GRG)}

Nilai GRG merupakan nilai konversi optimasi multi respon menjadi satu respon. Nilai GRG didapakan dari Persamaan 2.6

$$
\Gamma\left(x_{0}, x_{i}\right)=\frac{1}{n} \sum_{j=1}^{n} \gamma\left(x_{o j}, x_{i j}\right)
$$

Nilai GRG digunakan untuk menentukan titik optimum. Nilai GRG terbesar menunjukkan titik optimum [3]

Menentukan titik optimum melalui plot pengaruh utama GRG.

Penentuan titik optimum dapat dilakukan melalui plot pengaruh utama dari GRC. Titik optimum diambil dari taraf faktor yang memberikan nilai GRG tertinggi.

\section{HASIL DAN PEMBAHASAN}

Kasus yang digunakan dalam penelitian ini adalah percobaan optimasi karakteristik kualitas leadslag perisai radiasi beton menggunakan desain taguchi L9. Faktor dan respon diberikan pada Tabel 1.1. Struktur desain L9 beserta taraf faktor yang digunakan diberikan pada Tabel 3.1. 
Tabel 3.1. Desain Taguchi L9

\begin{tabular}{cccccc}
\hline No & Ortogonal & A & B & C & D \\
\hline 1 & A1B1C1D1 & 0,42 & 330 & 40 & 0,05 \\
2 & A1B2C2D2 & 0,42 & 360 & 50 & 0,1 \\
3 & A1B3C3D3 & 0,42 & 390 & 60 & 0,15 \\
4 & A2B1C2D3 & 0,45 & 330 & 50 & 0,15 \\
5 & A2B2C3D1 & 0,45 & 360 & 60 & 0,05 \\
6 & A2B3C1D2 & 0,45 & 390 & 40 & 0,1 \\
7 & A3B1C3D2 & 0,48 & 330 & 60 & 0,1 \\
8 & A3B2C1D3 & 0,48 & 360 & 40 & 0,15 \\
9 & A3B3C2D1 & 0,48 & 390 & 50 & 0,05 \\
\hline
\end{tabular}

Terdapat sembilan perlakuan yang dicobakan. Nilai respon yang diamati diberikan pada Tabel 3.2.

Tabel 3.2. Respon Percobaan

\begin{tabular}{ccccc}
\hline No & Y1 & Y2 & Y3 & Y4 \\
\hline 1 & 35 & 2631 & 42,23 & 0,1868 \\
2 & 60 & 2641 & 46,00 & 0,1852 \\
3 & 90 & 2639 & 48,00 & 0,1923 \\
4 & 65 & 2618 & 44,06 & 0,1808 \\
5 & 65 & 2670 & 44,10 & 0,1960 \\
6 & 105 & 2550 & 46,06 & 0,1763 \\
7 & 75 & 2681 & 41,87 & 0,1804 \\
8 & 115 & 2548 & 46,20 & 0,1716 \\
9 & 110 & 2570 & 44,60 & 0,1812 \\
\hline
\end{tabular}

\section{a. Hasil analisis konversi dengan desirability function.}

Tujuan optimasi dalam kasus ini adalah memaksimumkan keempat respon. Dengan demikian digunakan Persamaan 2.1 untuk mengkonversi keempat respon menggunakan larger-the-better. Hasil konversi diberikan pada Tabel 3.3.

Tabel 3.3. Konversi Respon dengan Desirability Function

\begin{tabular}{ccccc} 
No & $\mathrm{d} 1$ & $\mathrm{~d} 2$ & $\mathrm{~d} 3$ & $\mathrm{~d} 4$ \\
\hline 1 & 0,0000 & 0,8111 & 0,1080 & 0,5833 \\
2 & 0,5485 & 0,8511 & 0,6028 & 0,6960 \\
3 & 1,0000 & 0,8911 & 1,0000 & 0,8087 \\
4 & 0,7077 & 0,8394 & 0,4104 & 0,3395 \\
5 & 0,6546 & 1,0000 & 0,2766 & 0,8477 \\
6 & 1,0000 & 0,0000 & 0,8161 & 0,2637 \\
7 & 0,8139 & 1,0000 & 0,0842 & 0,4911 \\
8 & 1,0000 & 0,0000 & 0,6237 & 0,0000 \\
9 & 1,0000 & 0,3028 & 0,4899 & 0,4153 \\
\hline
\end{tabular}

Nilai desirability yang bernilai 1 artinya respon tersebut mendekati nilai target yang diinginkan. Sedangkan nilai desirability 0 berarti jauh dari target yang diinginkan. 


\section{b. Hasil penentuan nilai Grey Relation Coefficient}

Penentuan nilai GRC dilakukan dengan menentukan terlebih dahulu nilai $\Delta_{i j}$ yang merupakan perbedaan absolut antara nilai $x_{0}(j)$ dengan $x_{i}(j)$. Nilai $x_{0}(j)$ merupakan nilai desirability terbesar pada masing-masing respon. Nilai GRC dari keempat nilai desirability diberikan pada Tabel 3.4

\begin{tabular}{ccccc}
\multicolumn{5}{c}{ Tabel 3.4. Nilai Grey Relation Coefficient } \\
\hline No & GRC1 & GRC2 & GRC3 & GRC4 \\
\hline 1 & 0,3333 & 0,7258 & 0,3392 & 0,6159 \\
2 & 0,5255 & 0,7705 & 0,5355 & 0,7365 \\
3 & 1,0000 & 0,8212 & 1,0000 & 0,9159 \\
4 & 0,6311 & 0,7569 & 0,4371 & 0,4547 \\
5 & 0,5915 & 1,0000 & 0,3876 & 1,0000 \\
6 & 1,0000 & 0,3333 & 0,7134 & 0,4205 \\
7 & 0,7287 & 1,0000 & 0,3333 & 0,5431 \\
8 & 1,0000 & 0,3333 & 0,5489 & 0,3333 \\
9 & 1,0000 & 0,4176 & 0,4730 & 0,4950 \\
\hline
\end{tabular}

Setelah didapatkan nilai GRC pada masing-masing respon selanjutnya nilai GRC tersebut dikonversi dengan nilai Grey Relation Grade.

\section{c. Hasil penentuan nilai Grey Relation Grade (GRG)}

Penentuan nilai GRG dilakukan untuk mengkonversi keempat nilai GRC menjadi satu nilai sebagai ukuran optimasi. Nilai GRG diperoleh melalui Persamaan 2.6. pada dasarnya nilai GRG merupakan nilai rata-rata dari semua rspon. Pada beberapa literatur ada yang menggunakan nilai GRG ini sebagai nilai rata-rata terboboti dari nilai GRC. Nilai GRG tanpa pembobotan diberikan pada Tabel 3.5

Tabel 3.5. Nilai Grey Relation Grade

\begin{tabular}{ccc}
\hline No & Ortogonal & GRG \\
\hline 1 & A1B1C1D1 & 0,5036 \\
2 & A1B2C2D2 & 0,6420 \\
3 & A1B3C3D3 & 0,9343 \\
4 & A2B1C2D3 & 0,5700 \\
5 & A2B2C3D1 & 0,7448 \\
6 & A2B3C1D2 & 0,6168 \\
7 & A3B1C3D2 & 0,6513 \\
8 & A3B2C1D3 & 0,5539 \\
9 & A3B3C2D1 & 0,5964 \\
\hline
\end{tabular}

Nilai GRG terbesar menunjukkan titik optimum. Nilai GRG pada Tabel 3.5 menunjukkan bahwa nilai GRG terbesar adalah 0,9343 dihasilkan dari perlakuan A1B3C3D3. Dengan demikian perlakuan yang menghasilkan respon optimum adalah faktor A (perbandingan air-semen) 0,42, faktor B (kandungan semen) $390 \mathrm{Kg} / \mathrm{m}^{3}$, faktor $\mathrm{C}$ (perbandingan volume lead-slag agregat) $60 \%$ dan faktor D (perbandingan silika-semen) 0,15 .

\section{d. Hasil penentuan titik optimum melalui plot pengaruh utama GRG}

Plot pengaruh utama dari nilai GRG merupakan rata-rata nilai GRG pada masing-masing taraf faktor yang dicobakan. Hasil plot pengaruh utama GRG diberikan pada Gambar 3.1 


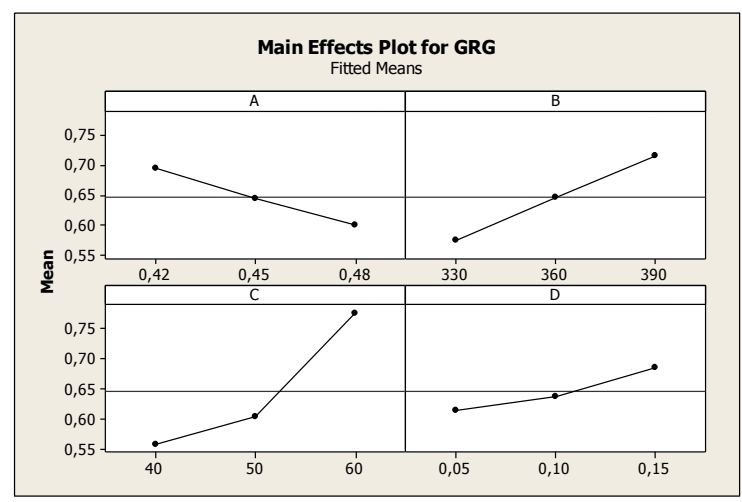

Gambar 3.1. Plot Pengaruh Utama Nilai GRG

Pada plot pengaruh utama nilai GRG pada Gambar 3.1 didapatkan bahwa pada faktor A (perbandingan semen-air) nilai GRG tertinggi diberikan pada taraf 0,42. Nilai GRG tertinggi pada faktor B (kandungan semen) diberikan pada taraf $390 \mathrm{Kg} / \mathrm{m}^{3}$. Pada faktor C (perbandingan volume lead-slag agregat) taraf $60 \%$ dan pada faktor D (perbandingan silika-semen) diberikan pada taraf 0,15. Dengan demikian titik optimum dihasilkan pada perlakuan A1B3C3D3.

Untuk mengetahui ketepatan dari titik optimum yang didapat perlu dilakukan percobaan konfirmatori dengan mencobakan perlakuan optimum tersebut.

\section{KESIMPULAN}

Analisis Optimasi multi respon dengan metode grey-taguchi desirability function yang diterapkan pada kasus optimasi karakteristik kualitas lead-slag perisai radiasi beton didapatkan perlakuan faktor A (perbandingan air-semen) 0,42, faktor B (kandungan semen) $390 \mathrm{Kg} / \mathrm{m}^{3}$, faktor C (perbandingan volume lead-slag agregat) $60 \%$ dan faktor $\mathrm{D}$ (perbandingan silika-semen) 0,15 .

\section{DAFTAR ACUAN}

[1] Akcay H., Anagun A.S. Multi Response Optimization Application on A Manufacturing Factory. Mathematical Aplications. 2013 Volume. 18 No. 3. pp. 531-538

[2] B. Munmun, P. Kali. Multi Response Optimization of Machining Parameters in Electro Discharg Machining of AISI 304 Using Desirability with Grey Relation Analysis. IJPRET, 2015, Volume 3(9). pp 15-22

[3] D. Saurav, S.M. Siba. Modeling, Simulation and Parameric Optimization of Wire EDM Process Using Response Surface Methodology Coupled With Grey-Taguchi Technique. International Journal of Engineering, Science and Technology. Vol 2, No. 5, 2010, pp. 162 183

[4] F. Anwar, M. Habshah. Multi-Response Optimization via Desirability Function for the Black Liquor DATA. Journal of Science and Technology. pp. 91-101

[5] Prajina N. V., Multi Response Optimazation of CNC End Milling Using Response Surface Methodology and Desirability Function. International Journal of Engineering Research and Technology ISSN 0974-3154 Volume 6, Number 6 (2013), pp. 739-746.

[6] Yodollahi. A, Ajorloo. A.M, Zolfaghari. A. Application of Grey-Taguchi Method for Simultaneous Optimization of Multiple Quality Characteristics in Lead-Slag Radiation Shealding Conrete. Boson Journal of Modern Physics (BJMP). 2015. Volume 2 issue 1. pp. 60-72.

[7] Montgomery DC. 2013. Design and Analysis of Experiments. Ed ke-8. New York: John Wiley \& Sons, inc. 
Spektra: Jurnal Fisika dan Aplikasinya

http://doi.org/10.21009/SPEKTRA
Volume 1 Nomor 2,

Desember 2016
p-ISSN: 2541-3384

e-ISSN: 2541-3392 